\title{
Os adjetivos qualificativos presentes nos DPs referenciais do português brasileiro
}

\section{Qualifying adjectives in referential DPs in Brazilian Portuguese}

Cristina de Souza Prim

UDESC

cristinaprim@gmail.com

Resumo: Buscamos apresentar uma nova forma de analisar a sintaxe e a semântica dos adjetivos que ocorrem dentro dos NP/DPs do português brasileiro. Defendemos que os adjetivos são gerados à direita do nome, em adjunção, com exceção dos exclusivamente pré-nominais, e que são os adjetivos, e não os nomes, que se movem para uma posição mais alta que o nome. A motivação do movimento parte do determinante, que, a depender de seus traços, oferece ambiente para hospedagem do adjetivo qualificativo movido. No caso dos DPs referenciais, o determinante que é específico projeta uma categoria TopP, capaz de receber o adjetivo, também específico. Caso o determinante não seja específico, não há projeção que possa receber o adjetivo qualificativo, pois TopP não é projetado nestes casos, e, por isso, o adjetivo não pode se mover. Esta proposta dá conta de explicar o comportamento dos adjetivos qualificativos nos DPs referenciais do português.

Palavras-chave: movimento do adjetivo; tópico; especificidade; adjetivos qualificativos. 
Abstract: We sought to present a new way of analyzing the syntax and semantics of adjectives in NP/DPs of Brazilian Portuguese. We argue that adjectives are generated on the right side of the noun, as adjuncts, except the exclusively prenominal ones, and that adjectives, not nouns, move to higher positions. Regarding the referential DPs, the specific determiner projects a TopP category able to receive the adjective, which is also specific. If the determiner is not specific, there is no projection to receive the qualifying adjective because, in this case, there is not a projected TopP, and, therefore, the adjective cannot be moved. This proposal explains the behavior of qualifying adjectives in Portuguese referential DPs.

Keywords: adjective movement; topic; specificity; qualifying adjectives.

Recebido em 23 de junho de 2015. Aprovado em 09 de novembro de 2015.

Este trabalho tem como objetivo entender quais são as regras sintáticas envolvidas no posicionamento dos adjetivos que podem ser pré e pós-nominais no português brasileiro, ou seja, dos adjetivos qualificativos. Deve-se dizer que nem sempre a explicação para o posicionamento do adjetivo pode ser unicamente sintática, mas é a sintaxe que determina quais são os contextos possíveis de se ter um mesmo adjetivo podendo ocupar a posição anteposta ou posposta ao nome, e é neste critério que queremos nos debruçar.

São muitos os trabalhos que se dedicam a explicar esse fenômeno. De modo geral, na literatura, estabelece-se uma relação entre a leitura do adjetivo e a posição que este ocupa no DP, ou seja, estabelecem que a posição do adjetivo e sua interpretação possuem interdependência. Essas propostas (para citar apenas algumas das propostas mais difundidas na literatura: Cinque (1993, 2010), Crisma (1990, 1993, 1996), Bernstein (1993)) falham ao não prever que o nome ou o determinante exerçam qualquer papel na escolha e na posição do adjetivo que possa se concatenar no DP/NP. Em (1) vemos que o adjetivo sensual ocupa a mesma posição nos exemplos (1a) e (1b), mas somente em (1a) temos ambiguidade do adjetivo: Maria baila sensualmente ou Maria é sensual e é bailarina. Em 
(1b), não é possível a leitura de que Maria administra sensualmente. A única diferença entre esses exemplos é o tipo de nome que acompanha o adjetivo pós-nominal. Já em (2), a possibilidade de ocorrência do adjetivo qualificativo na posição pré-nominal está ligada ao tipo de determinante que encabeça o DP. Diferentemente de (2a), (2b) é agramatical como sentença genérica - mas, é preciso dizer, não como sentença episódica.

a. Maria é uma bailarina sensual.

b. Maria é uma administradora sensual.

a. Uma brutal agressão deixa marcas na mente da vítima.

b. *A brutal agressão deixa marcas na mente da vítima.

Buscamos assim formas de explicar esses dados. Neste trabalho, argumentaremos que os adjetivos qualificativos são gerados na posição pós-nominal, na qual estabelecem relação com o nome que o antecede, e se movem para a posição pré-nominal se o determinante oferecer ambiente de hospedagem para esse adjetivo. Atentamo-nos primeiramente às características desses adjetivos.

\section{Características dos adjetivos qualificativos}

Os adjetivos qualificativos podem se combinar com Ns variados e possuem características morfossintáticas próprias que os distinguem dos outros adjetivos exclusivamente pré ou exclusivamente pós-nominais. Nem todos os qualificativos possuem todas as propriedades que listaremos a seguir; por outro lado, se o adjetivo pós-nominal possuir qualquer uma delas, já se torna claro que o adjetivo pertence a essa classe.

A primeira característica já foi mencionada: alguns desses adjetivos podem ocorrer também na posição anteposta ao nome, mas se percebe que há alguns qualificativos que ocorrem somente na posição pós-nominal em português, como é o caso de comum em (4). Este também pode ser um argumento para a nossa proposta de que os adjetivos qualificativos são concatenados primeiramente na posição pós-nominal, como vamos defender na próxima seção deste trabalho.

(3) a. O livro maravilhoso que quero te recomendar

b. O maravilhoso livro que quero te recomendar 
a. Um pássaro comum

b. *Um comum pássaro ${ }^{1}$

A segunda característica é a possibilidade de nominalização de alguns dos adjetivos que pertencem a essa classe. Em (5a), temos um caso de ambiguidade entre a leitura relacional ${ }^{2}$ (em que popular indica um estilo de música) e a qualificativa (em que o adjetivo significa conhecida). Quando nominalizado, a leitura relacional desaparece (cf (5b)). Por outro lado, devemos dizer que esses adjetivos não formam nomes sistematicamente, como mostra (6).

a. Música popular

b. A popularidade da música

(6) a. Separação dolorosa

b. *A dolorosidade da separação

Ao contrário do que a característica anterior pode nos fazer pensar, a classe a que o adjetivo pertence não pode ser determinada pelos sufixos que podem ou não ocorrer. Isso porque as classes de adjetivos não são formadas com bases léxicas, e isso significa que adjetivos formados pelos mesmos sufixos podem pertencer a classes diferentes em situações diferentes. No entanto, como os adjetivos exclusivamente pré ou exclusivamente pós-nominais não permitem modificação por advérbio de grau, é esperado que os sufixos -íssimo e de diminutivo só ocorram com adjetivos qualificativos, o que de fato ocorre.
a. Menina bonita
b. Menina muito bonita
c. Menina bonitíssima
d. Menina bonitinha

No entanto, alguns adjetivos, como constitucional, legal, gramatical, ocorrendo como adjetivo qualificativo, tampoco aceitam modificação por advérbio de grau. A razão parte de fora da linguagem

${ }^{1}$ Uma exceção seria “comum acordo", que é uma expressão pronta que significa "com o assentimento de todos" e não "mero acordo".

${ }^{2}$ Chamamos de relacional a classe dos adjetivos exclusivamente pós-nominais. 
- regras não são graduáveis. Esses adjetivos não aceitam modificação por muito, mas sim por completamente, absolutamente etc.

Além dessas características, apontamos ainda que os adjetivos qualificativos ocorrem com mais naturalidade na posição predicativa do que os outros tipos de adjetivos. Mas, como dissemos, nem todos os qualificativos possuem todas essas propriedades, mas ao menos uma delas. Chamamos a atenção que o adjetivo comum em (4) não pode ocorrer em posição pré-nominal, mas aceita modificação e ocorre em posição predicativa; o adjetivo doloroso em (6) não pode ser nominalizado, mas pode ocorrer na posição anteposta ao nome e sofrer modificação por advérbio, ocorrendo em posição predicativa.

Já mencionamos que queremos defender que esses adjetivos sejam gerados à direita de $\mathrm{N}$, em posição de adjunção. Esta não é a teoria mais aceita para adjetivos, e por isso vale nos alongarmos nesta discussão.

\section{Adjetivos qualificativos e a adjunção à direita}

Uma das razões que temos para defender que os adjetivos com posicionamento variável (e os exclusivamente pós-nominais) são gerados no campo pós-nominal é baseada em NPs do PB. Segundo a proposta de Espinal e McNally (2011), os nomes nus podem ser tanto NPs quanto DPs. NPs, que seriam nomes contáveis nus não especificados para número e definitude, ocorrem como objeto de uma reduzida classe de predicados relacionados com as estruturas ter $+N P$, e têm leitura de propriedade. Não saturam, só modificam o predicado, ou seja, não ocorrem em posição argumental, e por isso não se pode substitui-los por um pronome, visto que os pronomes indicam uma descrição definida. Essa proposta segue os princípios de Longobardi (1994), que defende que "uma expressão nominal é um argumento somente se é introduzido por uma categoria D. DP pode ser um argumento, NP não pode" (LONGOBARDI, 1994, p. 628, tradução nossa).

No exemplo a seguir, apresentado por Cyrino e Espinal (2014), temos vestido de festa como um NP que está modificando um predicado do mesmo tipo de ter (have-predicates) e que não pode ser retomado por um pronome anafórico.

${ }^{3}$ No original: "a nominal expression is an argument only if it is introduced by a category D. DP can be an argument, NP cannot". 
(8) Maria usa $\left[_{\mathrm{NP}}\right.$ vestido de festa] só quando suas amigas compram *ele/Ø de presente para ela.

Já DPs são os outros nomes nus definidos, ainda que não se apresentam especificados morfologicamente, são expressões do tipo existenciais que podem ser retomadas por pronome, como mostram os exemplos abaixo:

(9) O João tem [ ${ }_{D P}$ maçã verde] na cesta. Comprou ela/elas/Ø ontem.

(10) Maria usa $\left[{ }_{D P}\right.$ vestido novo] só quando suas amigas compram ele/Ø de presente para ela.

Os NPs do português apresentam evidência clara de que os adjetivos exclusivamente pós-nominais (como amarelo em (11)) e os que intercambiam de posição (como bonito em (12)) não podem ser gerados no campo pré-nominal, pois se esperaria que nesses casos não encontrássemos nenhuma diferença entre os adjetivos exclusivamente pré-nominais e esses adjetivos mencionados. No entanto, os exemplos (11-12) nos mostram que os adjetivos pós-nominais são possíveis tanto em NPs (ver (11a) e (12a)) quanto em DPs (ver (11b) e (12b)). Já na posição pré-nominal não podem ocorrer em NPs nem adjetivos que têm posicionamento variável (como bonito)) nem adjetivos exclusivamente pré-nominais (como é o caso de provável). Em (13) e (14) podemos ter adjetivos pré-nominais porque o sintagma é obrigatoriamente um DP, e a possibilidade de retomada pelo pronome comprova que não se trata de uma propriedade, mas de um indivíduo, um argumento do verbo.

(11) a. Maria usa vestido amarelo só quando suas amigas compram *ele/*eles para ela.

b. Maria usou um vestido amarelo porque suas amigas compraram ele para ela.

(12) a. Maria usa vestido de festa bonito só quando suas amigas compram *ele/*eles para ela. (Ao menos em uma das interpretações)

b. Maria usou um vestido de festa bonito porque suas amigas compraram ele para ela. 
(13) Maria usa bonito vestido de festa só quando suas amigas compram ele para ela.

(14) Maria usa provável vestido de noiva da sua irmã no Expo Noivas e Festas porque ele combina muito com ela também.

Uma teoria que postula que todos os adjetivos são gerados de forma semelhante na posição pré-nominal, como ocorre com as teorias mencionadas anteriormente, é incapaz de prever essas diferenças de comportamento entre adjetivos que podem ocorrer em NPs ou só em DPs. Em (20) apresentaremos a diferença entre as estrutura do DP e do NP, para facilitar a compreensão da proposta.

Apresentamos ainda outro fato que só a adjunção à direita pode dar conta: os adjetivos gerados na posição pós-nominal são selecionados ${ }^{4}$ pelo nome que o antecede, diferentemente dos adjetivos exclusivamente pré-nominais. Explicamos: adjetivos como mero, pretenso e suposto, por exemplo, podem se combinar com qualquer tipo de nome, como mostram os exemplos abaixo.

(15) Um mero homem/problema/sentimento/papel de carta/arroz integral

(16) Um pretenso batuqueiro/direito de mentir/sindicato/livro de histórias infantis

(17) Um suposto assassino/solução para o problema/separação/livro didático

Já os adjetivos pós-nominais, de qualquer que seja a classe a que pertençam, têm seu significado determinado pelo nome que o acompanha; em outras palavras, seu significado depende do campo semântico do nome. Em (18), temos o nome invasão, que não se combina com adjetivos de cor, a menos que esta cor se refira a algum grupo em específico: amarelo seria aceitável neste

\footnotetext{
${ }^{4}$ Usamos o termo seleção, talvez, na falta de uma opção melhor. Na literatura costumase utilizar o termo seleção para argumentos, o que não cremos que os adjetivos sejam. Utilizamos o termo seleção neste trabalho no sentido de que os adjetivos pós-nominais têm seu significado e sua ocorrência dependentes do nome que os antecede.
} 
caso se estiver se referindo a orientais, mas não à cor amarela. Em (18) vemos também que os adjetivos qualificativos, que têm posicionamento variável, também sofrem essa mesma restrição: o adjetivo atenciosa também tem sua ocorrência dependente do campo semântico do nome que o acompanha; invasões não podem ser atenciosas, mas invasores sim.

(18) Uma invasão ibérica/*amarela/*integral/*muito atenciosa.

(19) O colapso mental/*assombrado/?carnívoro/*rosado.

Essa característica mostra claramente que os adjetivos exclusivamente pré-nominais têm um comportamento diferente dos outros tipos de adjetivos, e que a geração de todos os adjetivos à esquerda do nome, em posições de especificador, é incapaz de prever essas diferenças de comportamento.

Sobre os qualificativos pós-nominais, portanto, defendemos que eles são gerados abaixo de NP, em adjunção ao nome, diretamente na posição pós-nominal.

a.

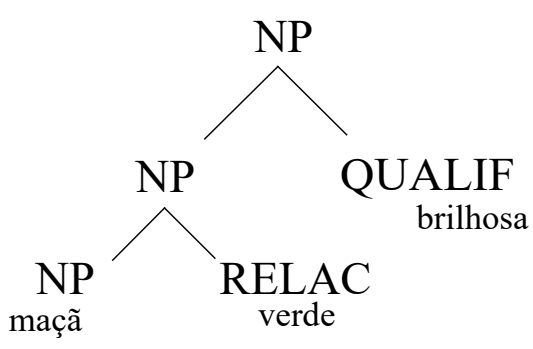

b.

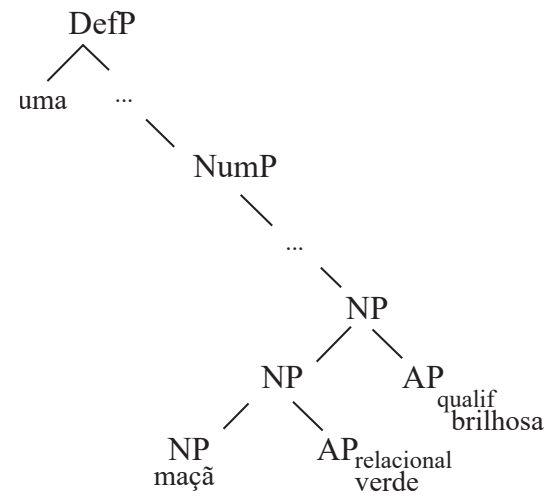

O que apresentamos em (20a) acima é a estrutura de NPs contendo adjetivos pós-nominais, relacionais e qualificativos, sugerida para o PB com base na proposta de Espinal e McNally (2011) comentada anteriormente: sem número e sem determinante. Já vimos que os adjetivos pós-nominais ocorrem em NPs sem restrições, diferentemente dos adjetivos pré-nominais, o que indica que as projeções dos adjetivos relacionais e 
qualificativos estão todas abaixo de NP. Em (20b), apresentamos como seria a estrutura do DP no caso dos adjetivos pós-nominais. A estrutura do DP contém definitude e número ${ }^{5}$ na representação, mas não descartamos a possibilidade de outras projeções.

\section{Os adjetivos qualificativos pré-nominais e os determinantes}

Defenderemos que os adjetivos pré-nominais podem ser de dois tipos - exclusivamente pré-nominais ou qualificativos pré-nominais. Os primeiros nos oferecem razões para estipularmos que são gerados numa posição mais alta que o nome; já os segundos, os qualificativos, como dissemos anteriormente, são gerados no campo pós-nominal, mas também podem ocorrer antepostos ao nome. Defenderemos que esses APs se movem para a posição pré-nominal se motivados pelo determinante, ou seja, ele é força motriz, desencadeadora do movimento do adjetivo.

Não há nenhum estudo sobre o PB que se debruce sobre essa mesma hipótese; mesmo nos trabalhos sobre outras línguas, por vertentes gerativistas ou não, encontramos poucas propostas que possam nos servir de base teórica.

Por outro lado, a intuição parece simples. Se levarmos em consideração que um DP definido é essencialmente anafórico ${ }^{6}$, não nos surpreenderemos com o fato de que um adjetivo pré-nominal antecedido por artigo definido seja em geral interpretado não-restritivamente, visto que a referência a um único indivíduo já está estabelecida pelo determinante, e não deve haver alternativas salientes. $\mathrm{O}$ mesmo não ocorre com um determinante indefinido, que não possui leitura anafórica e pode ser usado na introdução de um tema no discurso, ou quando há irrelevância de se apresentar o referente, ou mesmo quando há escolha livre do referente. Isso faz que a leitura restritiva, assim como a nãorestritiva, seja possível para o adjetivo em DPs indefinidos. O exemplo

\footnotetext{
${ }^{5}$ Número, segundo proposta de Espinal e McNally (2011), não estaria presente em todos os DPs referenciais, diferentemente de definitude, como por exemplo em DPs com nomes de massa., mas optamos por apresentá-lo aqui para que fique claro em qual posição defendemos seu aparecimento no DP.

${ }^{6}$ Esta é uma visão geral, mas não um consenso. Ver, por exemplo, Definite description processing in unrestricted text, de Renata Vieira (1998).
} 
(21) mostra que a leitura não-restritiva ou restritiva também depende de pressuposição no discurso familiar: conseguimos ter leitura não-restritiva em (21a) se houver familiaridade discursiva com o estereótipo dos contestatários como perigosos. Já (21b) não tem leitura não-restritiva, mas apenas restritiva. Isto porque no discurso familiar não há a informação compartilhada de que os contestatários são sempre pessoas brilhantes. O mesmo não ocorre com o determinante definido, como mostra (22). Com o artigo definido, não há leitura restritiva do adjetivo pré-nominal; a referência a um único indivíduo já está estabelecida pelo determinante, então não é possível que o adjetivo restrinja ainda mais o referente.

(21) a. Eduardo é considerado pela mídia um perigoso contestatário.

b. Eduardo é considerado pela mídia um brilhante contestatário.

(22) a. O perigoso contestatário se chama Eduardo.

b. O brilhante contestatário se chama Eduardo.

\section{Adjetivos qualificativos pré-nominais}

Os adjetivos dessa classe podem ocorrer na posição pré-nominal quando se referem a uma propriedade de um indivíduo em particular. Em (23b), entende-se que o falante deve ter alguém em específico na sua mente, ainda que o ouvinte não seja capaz de identificar o referente. Em (24), não é possível imaginarmos que o falante esteja pensando em alguma ideia em particular, e assim o adjetivo pré-nominal não ocorre nestes contextos. Mas a forma como o adjetivo aparece, como um superlativo, evidencia que o adjetivo é um qualificativo e isso nos faz questionar por que a sentença não é boa.

(23) a. Um advogado inteligentíssimo te chamará.

b. Um inteligentíssimo advogado te chamará.

(24) a. Me sugira uma ideia interessantíssima para o sábado à noite.

b. \#Me sugira uma interessantíssima ideia para o sábado à noite.

Na posição pós-nominal, o adjetivo inteligentíssimo em (23) significa que o falante tem um indivíduo em específico em mente, mas além disso é possível que o falante esteja se referindo a alguém 
não-específico, ou seja, qualquer um que seja um advogado bem inteligente. Essas duas possibilidades ocorrem em (23a). Em (24), como o contexto não permite a interpretação de que há uma ideia em particular, o adjetivo só pode ocorrer na posição pós-nominal, em que há a possibilidade de o adjetivo ser interpretado de outra forma que não a específica. $\mathrm{O}$ que vemos é que não é possível um adjetivo qualificativo pós-nominal ser específico e não ocorrer na posição prénominal. $\mathrm{O}$ fato de o adjetivo poder ter a leitura específica nas duas posições evidencia que não se trata de dois adjetivos diferentes, mas do mesmo adjetivo movido.

Na seção seguinte, trataremos dos determinantes, suas limitações em contexto com adjetivos pré-nominais e os traços relevantes para a discussão. Isso se faz necessário dada a hipótese lançada neste trabalho: os determinantes oferecem condições para a ocorrência de adjetivos qualificativos pré-nominais.

\section{Determinantes: definitude e especificidade}

Defenderemos que o principal traço que sempre pode ser observado nos determinantes é a definitude, que, segundo Ihsane e Puskás (2001), seria responsável por selecionar um objeto na classe de possíveis objetos. Visto dessa maneira, todos os determinantes possuem uma mesma origem, e o que os diferencia seria o traço [+/- definido]. Sobre seu status sintático-semântico, podemos dizer que cada determinante possui um papel substancial na leitura do DP.

Outra característica essencial para nossa discussão é a especificidade. Trata-se de uma noção semântico-pragmática que distingue diferentes interpretações de determinantes nos DPs. Carlson e Pelletier (1995) decidem chamar de DPs que se referem a um indivíduo particular de específicos e DPs que não se referem a um indivíduo particular de não-específicos - e neste caso, os determinantes não-específicos contribuem com conteúdo descritivo de sua asserção. Ihsane e Puskás (2001, p. 40) esclarecem que especificidade é relacionada a elementos pré-estabelecidos no discurso: o referente está ancorado em outro objeto do discurso. O que é decisivo na caracterização de especificidade não é o conhecimento ou a capacidade de identificar objetos, mas a intenção do falante em referir-se a um indivíduo determinado, independentemente de o ouvinte ser capaz de identificar o referente. Na literatura, essa distinção 
envolve em especial os indefinidos, mas mostraremos que essa distinção também se estende aos definidos e nus.

Os determinantes que serão estudados neste trabalho são os artigos definidos $o / a$, os indefinidos um/uma e os nus de nominais singulares. No português, os artigos definidos podem expressar tanto a referência a um indivíduo quanto a um kind, ou uma espécie (como em (25b)). São [+definidos], mas podem ser específicos ou não ${ }^{7}$ Um exemplo de definido específico está presente em (25a) e de não-específico em (25c).

(25) O estudante ganhará uma viagem a Argentina, o professor ao Canadá e o servidor ao Caribe.

a.Um estudante em particular, familiar ao falante.

b. Todo o grupo de estudantes (denotação de espécie).

c. Um estudante que teremos condições de identificar após o término do concurso.

Outro exemplo pode ser visto em (26), que pode ter leitura específica, se estivermos, por exemplo, considerando o trem das $15 \mathrm{~h} 32 \mathrm{~min}$, ou não-específica, se considerarmos o primeiro que passou com o destino desejado pela Maria.

(26) Maria pegou o trem.

Já o indefinido no PB pode ser um numeral e não fazer referência a um indivíduo em específico, ou pode ser alguém em específico, mas que o ouvinte não infere de quem se trata. Quando temos especificidade, o DP pode ser parafraseado por um certo, pois esse adjetivo marca leitura específica em indefinidos.

(27) Um estudante colou na prova.

a. Um (certo) estudante, que se chama João, colou na prova.

b. Um estudante, que eu ainda tenho que descobrir qual, colou na prova.

E finalmente, para falarmos sobre os nominais nus, retomaremos a discussão já iniciada sobre a distinção NP e DP. Relembrando a proposta de

${ }^{7}$ Os definidos não-específicos não são muito explorados pela literatura. Um trabalho que defende sua existência é o de Partee (1972). 
Espinal e McNally (2011): NPs seriam nomes contáveis nus não especificados para número e definitude, ocorrem como objeto de uma reduzida classe de predicados relacionados com as estruturas tem $+N P$, e têm leitura de propriedade. Por serem incapazes de saturar o predicado, não se pode substituilos por um pronome, visto que este indica uma descrição definida. Já os DPs nus podem ter leitura [-definida] específica (ver (28) e (29), em que o falante tem clara a sua referência) ou não-específica (conferir (30), em que não se pode dizer que haja uma entidade designada por funcionário novo).

(28) João viu menina bonita chorando na calçada.

(29) Eu conheci empresário que tava se ajudando.

(30) João está contratando funcionário novo.

Vimos então que DPs definidos, indefinidos e nus podem ser específicos ou não-específicos, portanto. Mas ainda é necessário deixar mais claro o papel da especificidade no DP, e é isto que faremos na próxima seção. Em seguida, apresentaremos uma proposta de aproximação do conceito de especificidade à categoria Tópico, uma ideia seguida por autores como Aboh et al. (2009) e Ihsane e Puskás (2001).

\section{DPs referenciais específicos e não-específicos}

Os DPs não-específicos foram estudados, possivelmente pela primeira vez, por Fodor (1970). A autora mostra por que não se deve considerar que os DPs referenciais são essencialmente específicos. Tratase de duas propriedades distintas: a referencialidade indica que há uma pessoa em particular, a especificidade indica que o falante sabe quem é o referente. Saber que há uma pessoa em particular não implica saber quem é esta pessoa. Em geral, assume-se que complementos de verbos existenciais exibem efeito de definitude, e por isso vamos nos restringir a essas sentenças neste momento.

(31) A Maria tem um primo que é astronauta.

No exemplo anterior, o falante pode saber que existe uma pessoa tal que a Maria é prima dessa pessoa e essa pessoa é astronauta. Isso 
não quer dizer que o falante saiba que essa pessoa é o João, mesmo que o falante conheça o João. Nessa situação, o falante não pode proferir a seguinte sentença:

(32) Tem um maravilhoso/atencioso/divertido/querido primo da Maria que é astronauta.

$\mathrm{O}$ adjetivo só pode ser prenominalizado se $\mathrm{o}$ falante souber quem é o referente em específico. Caso contrário, o adjetivo só poderá ser pós-nominal. No exemplo (33), o adjetivo pode ser pós-nominal porque a Maria disse que o primo é querido, e o falante reportou isto. Não é o julgamento do falante, e por isso o adjetivo não pode ser pré-nominal.

(33) A Maria tem um primo querido que é astronauta.

Outro exemplo com DP indefinido pode ser conferido a seguir. Há duas leituras referenciais possíveis, uma em que há um casaco caro e é esse que a Maria vai comprar (leitura específica) e outra em que há casacos caros, e dentre estes, a Maria vai comprar um (leitura nãoespecífica). (34b), com o adjetivo maravilhoso pós-nominal, pode ter ambas as leituras, diferentemente de (34c), que só pode ser específico ${ }^{8}$.

a. A Maria vai comprar um casaco caro.

b. A Maria vai comprar um casaco caro maravilhoso.

c. A Maria vai comprar um maravilhoso casaco caro.

O mesmo ocorre com determinantes nus, como mostram os próximos exemplos. Temos em (35a) uma sentença episódica, com DP existencial. O determinante é referencial, mas não necessariamente específico. Se específico, o adjetivo pode se mover para a posição pré-

\footnotetext{
${ }^{8} \mathrm{Em}(34 \mathrm{c})$, podemos ter uma leitura diferente do adjetivo pré-nominal se o falante considerar que todos os casacos caros são maravilhosos. Nesse caso, o adjetivo é um epíteto, ou seja, o adjetivo aponta uma característica comum a toda a classe formada por casaco caro. Não nos interessamos muito pelos epítetos neste trabalho, mas seria interessante estudar quais as motivações para um adjetivo qualificativo ter que ser obrigatoriamente pré-nominal quando epíteto. Eles apresentam certas semelhanças com alguns adjetivos exclusivamente pré-nominais, visto que possuem sempre leitura não-específica, assim como mero.
} 
nominal. Se não, ele ainda pode ocupar a posição pós-nominal (neste caso, apenas com leitura subespecífica ${ }^{9}$ ).
a. A Maria comprou livro no shopping.
b. A Maria comprou bom livro no shopping.
c. A Maria comprou livro bom no shopping.

Outros exemplos podem ser conferidos a seguir, nos quais o determinante é referencial, mas pode ou não ser específico. O movimento do adjetivo para a posição pré-nominal só ocorre com leitura específica. Já na posição pós-nominal, a leitura do adjetivo pode ser específica ou subespecífica.

a. Naquele baú eu vi saia.

b. Naquele baú eu vi saia linda pra você usar.

c. Naquele baú eu vi linda saia pra você usar.

Sobre os definidos, Partee (1972) sugere que também existem DPs definidos não-específicos, mas estes não seriam referenciais. No exemplo a seguir, baseado no exemplo clássico de Donnellan (1966), temos duas interpretações, a primeira com leitura referencial, ou seja, o falante sabe quem é o referente no mundo para "o assassino de Lennon", e a segunda com leitura atributiva, em que o falante entende que, quem quer que seja o assassino de Lennon, esta pessoa é insana.

O assassino de Lennon é insano.

Mas assim como Fodor (1970), defendemos que existem DPs definidos referenciais não-específicos, como mostra o exemplo (38), em que o DP se refere a uma pessoa em particular, mas o falante ainda não tem condições de identificá-lo. Nesse caso, como esperado, o adjetivo não

\footnotetext{
${ }^{9}$ Muitos autores, como Cinque (2010) postulam que a leitura do adjetivo pós-nominal seria não-específica. Não estamos de acordo; a intuição que temos é que a leitura não-específica ocorre quando o adjetivo não restringe de nenhum modo o nome que o acompanha. Esse seria o caso dos adjetivos epítetos. O termo subespecífico, foi utilizado por Bosque e Picallo (1996), e seguiremos o mesmo significado atribuído pelos autores ao termo: o adjetivo imediatamente seguinte ao nome denota uma classe maior do que aquele que o segue, que denota uma subclasse.
} 
pode ser movido, visto que não há leitura específica, mas pode ocorrer posposto ao nome, com leitura subespecífica.

(38) a. O professor mais votado ganhará um prêmio. (leitura nãoespecífica)

b. *O maravilhoso professor mais votado ganhará um prêmio.

c. O professor maravilhoso mais votado ganhará um prêmio.

Fica claro assim que os traços de definitude e especificidade podem não ocorrer ao mesmo tempo. Vejamos como pode se manifestar cada categoria na estrutura sintática.

\section{Relação entre especificidade e tópico}

Exploramos nesta subseção as vantagens de se separar definitude e especificidade dos DPs em duas categorias distintas. A definitude estaria associada a Def, diretamente, e sempre é projetada. Já a especificidade surge em uma categoria mais baixa na estrutura. Assim, o objetivo desta subseção é apresentar argumentos para se postular uma posição de tópico dentro da estrutura DP que conteria especificidade. A ideia de postular um tópico dentro do DP tem por base o paralelismo que comumente se faz entre a estrutura da sentença e do $\mathrm{DP}^{10}$. Deve-se dizer que o DP é defectivo em relação às propriedades funcionais encontradas em uma sentença, ou seja, a comparação que se faz não resulta em uma categoria nominal para cada categorial verbal. Não surpreenderia, assim, se categorias como tópico (e também foco) não estiverem presentes em DPs de todas as línguas.

O tópico estabelece uma relação entre a proposição e um indivíduo do discurso - a proposição expressa pela sentença será sobre o indivíduo.

\footnotetext{
${ }^{10} \mathrm{~A}$ respeito disto, ver Abney (1987), Giusti (2006) e outros trabalhos subsequentes. Magalhães (2004, p. 161) resume a proposta de Abney da seguinte forma: "No DP, D é o núcleo que seleciona o NP como complemento do mesmo modo que o VP funciona como complemento para Infl. Temos assim uma relação argumento/predicado entre D e N no sintagma nominal e sujeito e verbo no sintagma verbal. Na sentença, os traços de número são interpretáveis no sujeito (argumento) e não interpretáveis no verbo (predicado). O mesmo acontece no DP: traços de número são interpretáveis no D (argumento de N) e não interpretáveis em N (predicado)". Giusti, por sua vez, argumenta que a diferença entre as estrutura da sentença e do DP seria a noção de tempo, presente no primeiro, mas ausente no segundo. Para maiores detalhes, verificar os trabalhos dos autores citados.
} 
Em geral, o tópico se refere a um indivíduo que possui certo grau de atuação efetiva no discurso. O tópico também é usado em construções em que há deslocamentos para certas posições estruturais (ABOH et al., 2009, p. 4)

Sobre a presença da categoria ToP dentro do DP, Lambrecht (1994, p. 35, tradução nossa) afirma que " [...] os contrastes na estrutura de informação podem ser expressos, em princípio, dentro de qualquer domínio sintático que expresse uma relação predicado-argumento, como por exemplo dentro da estrutura nominal"11.

Alguns autores como Aboh et al. (2009) propõem posições de tópico e foco dentro de DP, de modo similar a Rizzi (1997). Aboh relembra alguns outros trabalhos relacionando movimento dos adjetivos a projeções funcionais como tópico ou foco. Siewierska e Uhlirova (1998, p. 134) afirmam que em polonês e em outras línguas eslavas o adjetivo qualificativo recebe uma leitura não-marcada na posição pré-nominal, e o posicionamento do adjetivo posposto ao nome indica foco contrastivo ou ênfase.
a. Piękna kobieta(polonês)
bonita mulher
b. Kobieta piękna
mulher bonita

Rijkhoff (1998) aponta que, em turco, o foco contrastivo ou enfático é obtido com o movimento do adjetivo para uma posição mais alta que a do artigo indefinido/cardinal bir. Sem foco, o adjetivo ocupa a posição entre o artigo e o nome.
a. Birbüyükev (turco)
Uma grande casa
b. Büyük bir ev
Grande uma casa

Em português, o adjetivo focalizado não pode ocupar a posição entre o DefP e o Nome, ao menos em DPs referenciais ${ }^{12}$. Defendemos que

\footnotetext{
${ }^{11}$ No original: "information structure contrasts may in principle be expressed within any syntactic domain which expresses a predicate-argument relation, for example within the noun phrase".

${ }^{12}$ Aparentemente, quando há leitura quantificacional do DP indefinido, podemos ter
} 
o DefP pode projetar TopP se houver especificidade do determinante, e nenhuma posição de foco é encontrada nesse mesmo ambiente. Como já dissemos, a comparação entre um DP e uma sentença não resulta em uma categoria nominal para cada categorial verbal, ou seja, o paralelismo não é perfeito, e ao menos em PB os adjetivos pré-nominais não oferecem argumentos para a postulação de uma projeção FocP em DPs referenciais. Os exemplos a seguir mostram adjetivos como brutal e maravilhoso recebendo foco contrastivo, o que torna o DP agramatical.

*A BRUTAL agressão, não aquela que foi verbal.

(42) *O MARAVILHOSO livro de receitas, não aquele outro todo light.

Sobre foco, Giusti (1996) afirma que o italiano não possui essa posição focal dentro da estrutura $\mathrm{DP}^{13}$. Ou seja, os adjetivos descritivos pré-nominais do italiano são sempre tópicos.
a. *i BIANCHI suoi capelli, non (quell) i neri
os brancos seus cabelos, não aqueles negros
b. *i suoi BIANCHI capelli, no (quell) i neri

Já sobre o tópico, Giusti (1996) argumenta que alguns adjetivos pré-nominais do italiano se referem a conhecimento compartilhado, e por isso estariam em Tópico. Giusti descreve o comportamento dos adjetivos do italiano através dos seguintes exemplos. Em (44a), há tanto a interpretação de que todo o seu cabelo é branco ou somente alguns fios são brancos; esta segunda interpretação não está disponível em (44b). Já (44c) pode significar que a brancura do cabelo é uma informação compartilhada ou dada no discurso.

\footnotetext{
adjetivos pré-nominais focalizados. Importante mencionar que a leitura do adjetivo qualificativo pré-nominal nunca é específica nestes casos, mas subespecífica, uma leitura que não está disponível quando o DP é referencial.

(i) Se eu quiser contratar um excelente professor, terei que entrevistar muita gente.

(ii) Esta revista mostra como fazer uma incrível viagem sem estresse.

${ }^{13}$ Seria interessante verificar o que ocorre com os DPs quantificacionais, dado o que apontamos na nota 12 .
} 
(44) a. I suoi capelli bianchi

os seus cabelos brancos

b. I suoi bianchi capelli

c. I bianchi, suoi capelli

A posição pré-nominal do adjetivo no italiano, descreve Giusti (1996), é mais favorável quando o adjetivo expressa uma propriedade prototípica do nome, ou seja, um epíteto, e quando o nome em si é maximamente especificado. Tanto em (44b) como em (44c), o adjetivo pré-nominal se refere a um conhecimento compartilhado no discurso.

A proposta de Giusti é que os adjetivos são gerados primeiramente em posição de especificador de uma projeção de concordância e depois se movem para SpecTopP.

$$
\left[{ }_{D P} \operatorname{Art}\left[_{\text {TopP }} A P_{j} \operatorname{Top}\left[{ }_{\text {AgrP }} \operatorname{Poss}\left[{ }_{\text {AgrP }} \ldots t_{j} \ldots \ldots\left[_{\text {AgrP }} \mathrm{N}_{\mathrm{i}}\left[\ldots \mathrm{t}_{\mathrm{i}}\right]\right]\right]\right]\right]\right.
$$

Sobre a aplicação desta proposta ao PB, já argumentamos contra a geração destes adjetivos numa posição mais alta que a do nome, e por conta disso, ela não será utilizada neste trabalho.

Ainda sobre TopP, Ihsane e Puskás (2001) também argumentam que o núcleo Top é caracterizado pelo traço [+específico]. Os autores não adotam um sistema de traços binários, ou seja, não adotam que essa projeção também possa validar traços [-específicos]. Argumentam que não é o caso que um sintagma possa ser relacionado ao discurso ou banido do discurso, mas sim que um não tópico simplesmente não contém conexão relevante com o discurso.

Especificidade [...] não parece se encaixar tão diretamente em um sistema binário. [...]: elementos podem ser específicos, e nesse caso eles são relacionados ao discurso; nos outros casos, eles são não-específicos, o que significa que eles não são relacionados ao discurso, em um sentido subespecífico. Essa assimetria nos dois traços levanta a questão da realização sintática dos traços relevantes ${ }^{14}$. (IHSANE; PUSKÁS, 2001, p. 42, tradução nossa).

\footnotetext{
${ }^{14}$ No original: "Specificity [... $]$ does not seem to fit so directly into a binary system [...]: elements may be specific, in which case they are related to the discourse; otherwise,
} 
Por isto, vamos propor que quando há especificidade no determinante, a projeção Tópico é selecionada por DP; se não há especificidade, não há projeção de tópico. Em outras palavras, DPs [+/- definidos] e [+específicos] projetam uma categoria TopP abaixo de DefP. A definitude está alocada em Def, e está sempre presente com o traço [+definido] ou [-definido]. Já a especificidade está presente com o traço [+específico] e está alocada em Top. Quando o DP não é específico, não há TopP presente na estrutura.

Tomemos o exemplo (46). Temos duas possibilidades de leitura, uma em que "um filósofo" é específico, e outra que é não-específico. Se o artigo indefinido estiver marcado com os traços [-definido, +específico], o traço [-definido] surge no lugar em que é concatenado o artigo, no núcleo de Def. Já a especificidade surge na seleção: determinantes específicos selecionam TopP (cf (47a)); não-específicos simplesmente não apresentam essa projeção (cf (47b)).

(46) Ana falou com um filósofo inteligente.

(47) a.

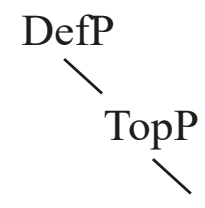

NumP

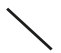

NP

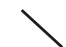

AP b.

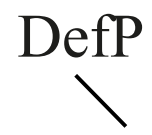

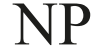

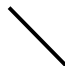

O artigo, portanto, que contém sempre o traço [+/- definitude], selecionará Top se houver especificidade no DP. Há, portanto, duas possibilidades de estrutura para o DP presente em (46): uma com marca de especificidade no DP, ou seja, com projeção Top (quando se sabe quem é o filósofo), e outra sem especificidade no DP e, portanto, sem

they are non-specific, which means that they are not related to the discourse, in an under-specified way. This asymmetry in the two features raises in turn the question of the syntactic realization of the relevant (set of) features". 
Top (para a interpretação de que era um filósofo que é inteligente, mas não se sabe exatamente quem seria essa pessoa).

Vale dizer, por fim, que em (47) estamos incluindo somente as projeções que são relevantes para a proposta, o que não anularia a possibilidade de se incluir outras categorias que possam se aplicar ao DP.

\section{Interação determinante e adjetivo}

Este trabalho tem como uma das hipóteses que o movimento do adjetivo ocorre quando o determinante que encabeça o DP oferece um lugar de pouso adequado para o adjetivo. Esta subseção tem como objetivo avançar nessa discussão apresentando como se dá a interação do determinante com o adjetivo pré-nominal.

Vejamos agora os resultados que encontramos quando controlamos as características do determinante e as propriedades dos adjetivos pré-nominais.

Os exemplos a seguir mostram que os adjetivos exclusivamente pré-nominais podem ocorrer tanto com DPs específicos quanto nãoespecíficos. Ainda que mais comumente os encontramos antecedidos por artigo indefinido, sintática e semanticamente não há impedimentos para a ocorrência desses adjetivos também com o definido ou o nu. $\mathrm{Ou}$ seja, além de aceitarem a combinação com determinantes contendo o traço [+/- definitude], esses adjetivos também podem ser específicos ou não-específicos/subespecíficos.

(48) Um grande amigo da Maria já foi piloto de caça. (é referencial, mas pode não ser específica/subespecífica)

(49) Uma mera/simples discussão surgiu e ele já queria desistir de tudo. (referencial específica ou não-específica/subespecífica)

(50) Tem um mero/suposto/pobre/grande concorrente se matando de estudar agora mesmo. (referencial específica ou não-específica/ subespecífica)

Os qualificativos, por sua vez, só podem ocorrer na posição pré-nominal se o determinante que encabeça o DP for específico (em DPs referenciais). Quanto aos traços de definitude, esses adjetivos não 
apresentam restrições na combinação. Em (51), o indefinido pode ser interpretado como específico ou não-específico. (51b) mostra que as duas interpretações do indefinido seguem válidas com o adjetivo posposto ao nome. (51c) mostra que o movimento do AP para a posição pré-nominal só ocorre quando o determinante tem leitura exclusivamente específica, seja [+ definida] ou [-definida]. O qualificativo pré-nominal não ocorre quando o indefinido é interpretado com outra leitura. (52) oferece mais dados para que se mantenham estas asserções: o adjetivo pós-nominal se combina com indefinidos específicos ou não-específicos (ou seja, a estrutura poderá ser (47a) ou (47b)), mas quando o adjetivo se move para a posição pré-nominal, este terá somente leitura específica, e a estrutura correspondente seria apenas (47a).

(51) a. Um professor foi premiado. - leitura específica ou nãoespecífica

b. Um professor maravilhoso foi premiado. - específica ou nãoespecífica

c. Um maravilhoso professor foi premiado. - leitura específica

(52) a. Eu falei com um filósofo.

b. Eu falei com um filósofo famoso.

c. Eu falei com um famoso filósofo.

Com os definidos não-específicos, vemos que também não há ocorrência de adjetivos qualificativos pré-nominais. Se no exemplo (53a) abaixo estivermos considerando que ainda não ocorreu a votação e que ainda não sabemos qual será o professor mais votado, o determinante não será específico, e a previsão de que neste caso não poderá ocorrer um adjetivo qualificativo pré-nominal é correta. Por sua vez, se imaginarmos que a votação já cessou e o falante sabe quem é especificamente o vencedor, o determinante definido será específico e o adjetivo poderá se mover para a posição pré-nominal.

(53) a. O professor mais votado ganhará um prêmio. (leitura nãoespecífica)

b. *O maravilhoso professor mais votado ganhará um prêmio.

c. O professor maravilhoso mais votado ganhará um prêmio. 
(54) a. O professor mais votado ganhou um prêmio. (leitura específica)

b. O maravilhoso professor mais votado ganhou um prêmio.

Os DPs nus também só permitem o aparecimento de adjetivos pré-nominais quando o determinante tem leitura específica. A leitura do DP em (55) deve ser específica, e por isso o adjetivo pode subir para a posição pré-nominal. Em (56), temos as duas possibilidades de leitura quando o adjetivo não está presente. Mas como mostra (56b), o adjetivo qualificativo pré-nominal só ocorre quando a leitura do determinante nu e do adjetivo é específica (considerando que nem todo peixe preparado é delicioso). Já em (57), temos obrigatoriamente uma leitura não-específica/subespecífica do indefinido. Neste caso, o XP que contém o adjetivo qualificativo não poderá se mover para a posição pré-nominal.

(55) a. Professor salvou família de moradores da Tijuca. (leitura específica)

b. Maravilhoso professor salvou família de moradores da Tijuca.

(56) a. João está preparando peixe. (específica ou não-específica)

b. João está preparando delicioso peixe para a janta. (específica)

(57) a. Caroline viu policial em todo canto da praça. (não-específica)

b. *Caroline viu charmoso policial em todo canto da praça.

c. Caroline viu policial charmoso em todo canto da praça.

Já está claro que os adjetivos qualificativos ocorrem em posição anteposta ao nome quando o determinante tem leitura específica, apenas ${ }^{15}$. Nesse caso, os adjetivos também terão leitura específica. Os

\footnotetext{
${ }^{15}$ As generalizações apresentadas acima parecem esbarrar em DPs envolvendo kinds. Esses DPs não podem ser específicos, o que nos faria pensar que esses DPs não aceitariam adjetivos qualificativos pré-nominais. No entanto, os exemplos abaixo mostram que adjetivos como inteligente e desdentado podem ocorrer na posição prénominal, nesses casos. Esses dados abrem uma discussão bastante interessante. Por um lado, esses adjetivos não podem ocorrer na posição pós-nominal nesses contextos, posição em que os qualificativos são gerados.
}

(i) $\mathrm{O}$ inteligente golfinho tem um focinho alongado formando um bico.

(ii) $\mathrm{O}$ desdentado tamanduá tem língua longa e pegajosa. 
exclusivamente pré-nominais, por sua vez, não apresentam nenhum tipo de interação com o determinante.

Diante do que foi exposto, é de se esperar que os qualificativos pós-nominais sejam selecionados apenas pelo nome com o qual se concatenam, mas não pelo determinante que encabeça a estrutura. De modo geral isto é ratificado pelos dados, mas há alguns exemplos que devem ser discutidos, e que serão apresentados a seguir.

\section{Há relação entre determinantes e adjetivos qualificativos pós-nominais?}

Argumentamos que os adjetivos qualificativos são gerados no campo pós-nominal. Postulamos que o movimento desses adjetivos para a posição pré-nominal ocorre somente se o determinante oferecer as condições necessárias para o movimento. Isso nos faz esperar que os determinantes não sejam selecionadores dos adjetivos qualificativos pós-nominais. Mas veremos que há alguns casos discutíveis.

Um dado problemático para esta proposta é apresentado por Demonte (1999, p. 65): em (58) temos um adjetivo qualificativo que não ocorre com naturalidade na posição pós-nominal (só quando há leitura de contraste) mas ocorre na pré-nominal quando o DP em questão é encabeçado por um definido. Com o determinante indefinido, esses adjetivos são possíveis tanto em posição pré quanto em posição pósnominal, ainda que não haja contraste.

(iii) $\mathrm{O}$ golfinho inteligente tem um focinho alongado formando um bico.

(iv) O tamanduá desdentado tem língua longa e pegajosa.

Em (iii), o nome perde a leitura de kind e se torna de um indivíduos e o adjetivo ocupar a posição pós-nominal. (iv) não seria pronunciada por um falante que tenha conhecimento do fato de que não existem tamanduás com dentes.

Vamos defender que a restrição não é linguística: esses adjetivos são qualificativos e o não aparecimento do qualificativo em posição pós-nominal de DPs kindsse deve à natureza restritiva da posição pós-nominal, que forçaria uma leitura de subkind, indesejada pelo falante que tem conhecimento de mundo e sabe sobre a falta de subkinds quando o DP em questão envolve esses nomes e adjetivos citados. Esses DPs não são referenciais, o que nos garante que o comportamento diferenciado dos exemplos supracitados contendo nomes kinds não afeta a proposta que estamos apresentando. Esse ponto está em aberto para pesquisas futuras. 
(58) a. *Colocou o chapéu horrível/belíssimo/maravilhoso.

b. Colocou o horrível/belíssimo/maravilhoso chapéu.

(59) a. Colocou um chapéu horrível/belíssimo/maravilhoso.

b. Colocou um horrível/belíssimo/maravilhoso chapéu.

Uma evidência de que esses adjetivos pós-nominais não estão sendo influenciados pelo determinante encontra-se nos exemplos que seguem, em que a presença de outro adjetivo pós-nominal legitima a presença do elativo pós-nominal em DP definido sem que a leitura de contraste seja obrigatória (cf (60)). Outra opção seria a presença de uma relativa, como em (61).

(60) Colocou o chapéu roxo belíssimo.

(61) Colocou o chapéu horrível que ganhou do irmão.

Leonetti (1999), que também discute a questão, aponta que muitos dos adjetivos qualificativos que bloqueiam o uso do definido em favor do indefinido são predicados factivos: os fatos que se apresentam como pressupostos são predicados que denotam juízos ou reações psicológicas, ou seja, que são voltados ao falante. O autor aponta que isto ocorre provavelmente porque o conteúdo semântico desses adjetivos enfáticos não os permite atuar como elementos restritivos e contribuir com a fixação do referente quando na ausência de outros modificadores. O mesmo é esperado, portanto, com outros adjetivos enfáticos, que só ocorrem com definidos se houver leitura contrastiva do adjetivo.

(62) João ficou lá motivando *o/um jogador incrível.

(63) Ela viu *o/um espetáculo magnífico.

(64) Protagonizou *o/um episódio absurdo/surpreendente/ emocionante/inesperado.

Mas a presença de mais material modificador também legitima o uso desses adjetivos com o determinante definido.

(65) O espetáculo magnífico que a Maria me recomendou ver. 
(66) Protagonizou o episódio absurdo/surpreendente/emocionante/ inesperado narrado pela Maria.

O uso de um advérbio de grau também faz supor que o falante registre sua opinião com o uso do adjetivo, e nestes casos a concatenação (merge) com determinante definido também é incompatível com nome e adjetivo qualificativo pós-nominal, pelas mesmas razões apontadas acima. Novamente o uso de mais material na posição posposta ao adjetivo qualificativo legitima a presença do adjetivo modificado.

a. ${ }^{\circ}$ o/um café bastante doce

b. O café bastante doce feito pela Maria

a. *a/uma novela muito ruim

b. A novela muito ruim que a Maria insiste em ver

Exploraremos a seguir uma proposta de movimento destes adjetivos da posição pós-nominal para a pré-nominal somente quando o determinante possui traço [+específico], ou seja, quando há projeção TopP marcando a especificidade. Essa projeção poderá receber o AP movido, pois ambos são marcados como [+específico].

\section{Proposta de estrutura}

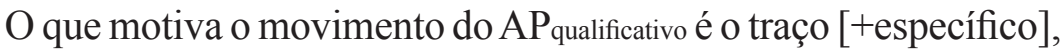
um traço que todos os determinantes em questão podem ter. Em contextos em que o DP indefinido é ambíguo, e pode conter tanto leitura específica quanto não-específica, a presença de um adjetivo qualificativo prénominal só ocorre quando o falante está considerando somente a leitura específica do determinante. Na posição pós-nominal, o adjetivo não força nenhuma leitura em especial do determinante. Picallo (1994) e Bosque (2001) mencionam que os adjetivos pré-nominais forçam a leitura específica do indefinido ${ }^{16}$. Ou seja, os autores defendem que o

${ }^{16} \mathrm{O}$ espanhol apresenta uma evidência adicional de que os pré-nominais devem ter leitura específica.

(i) Busco (a) un actor famoso

(ii) Busco *(a) un famoso actor 
adjetivo é capaz de cancelar uma das leituras do determinante indefinido. $\mathrm{O}$ que estamos argumentando é ligeiramente diferente: dizemos que o AP qualificativo é incapaz de mover-se se o determinante não for específico, isto é, se não a categoria Tópico não for projetada. Mas se houver Tópico projetado, o adjetivo poderá ter leitura específica quer esteja na posição pré-nominal quer esteja na pós-nominal. O movimento não é obrigatório, visto que os adjetivos pós-nominais também podem ser específicos. $\mathrm{O}$ movimento do adjetivo só pode ocorrer se os traços do determinante e do adjetivo forem igualmente [+específico].

Reforçamos que não cabe uma teoria em que o movimento do adjetivo seja obrigatório. A possibilidade do movimento sim, esta é licenciada pela sintaxe, deve-se reforçar. A maleabilidade no posicionamento do adjetivo não deve ser vista como um enfraquecimento da sintaxe, visto que esta predetermina quando pode ou não ocorrer esse movimento.

Se Tópico é projetado sempre que o determinante tem leitura específica, podemos dizer que um adjetivo pós-nominal específico tem como checar seus traços de especificidade por Agree, visto que a projeção que contém especificidade (TopP) está disponível ${ }^{17}$.

Partiremos de (47), retomado como (69) para discutirmos qual seria a estrutura que melhor explica os dados. O determinante da estrutura abaixo pode ser [+/- definido]. Independentemente do valor do traço, este estará marcado no núcleo Def. Essa estrutura também é compatível com um DP específico, visto que há uma projeção de Tópico proposta. Essa projeção viabiliza a subida do adjetivo, que encontra em TopP um lugar de pouso que também possui traço [+específico]. Em outras palavras, quando o D traz o traço [+específico], a categoria Top é projetada. Quando não há especificidade no DP, TopP não é projetado, o que garante que não haja problemas conhecidos na literatura como look ahead, ou seja, a

\footnotetext{
Quando específico, o objeto direto animado deve ser precedido da preposição $a$. Na posição pós-nominal, por sua vez, o adjetivo pode ter leitura não-específica, o que legitima a opcionalidade de uso da preposição em (i).

${ }^{17}$ Roberts (2007) aponta que a checagem por Agree, em contrapartida ao movimento, é uma tendência no percurso diacrônico das línguas, visto que checar é mais econômico que mover. Não podemos dizer, contudo, que está havendo uma mudança da posição dos qualificativos sem que se faça um estudo específico sobre esse ponto.
} 
falta da projeção de Tópico quando o DP não é específico garante que o adjetivo não se moverá se não for específico. Nossa proposta está de acordo com Aboh (2009) no que tange à possibilidade de projeções de Tópico dentro do DP, está de acordo com Giusti (1996), que defende que os adjetivos pré-nominais em italiano são topicalizados, e de acordo com Ihsane e Puskás (2001), que defende que a categoria Tópico é sempre [+específico].

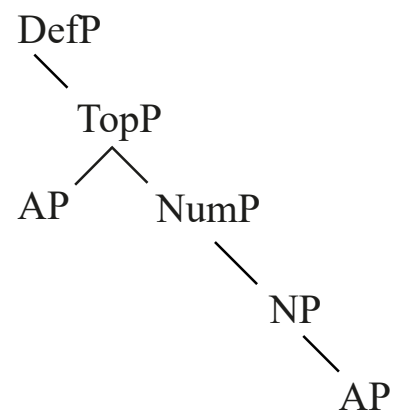

(70) a. Um brilhante físico nuclear

b.

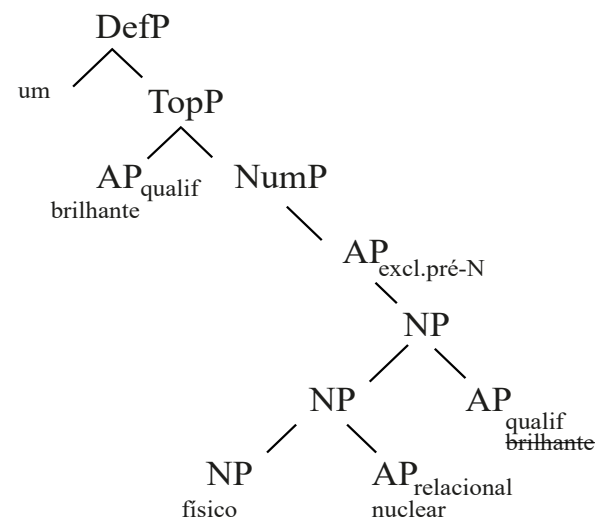




\section{Evidências de movimento por especificidade em diversas línguas}

Uma questão que nos colocamos é se há algum outro tipo de evidência independente mostrando que elementos portando o traço [+especifico] desencadeiam movimento. Abaixo, apresentaremos três evidências que demonstram movimentos motivados por especificidade em outros contextos do PB e também de outras línguas.

A primeira evidência é apresentada por Ihsane e Puskás (2001), que mostram que em húngaro o DP definido pós-verbal em exemplos como (71) tem leitura preferencialmente não-específica, mas na posição pré-verbal o DP é obrigatoriamente específico quando ocupa a posição de tópico.

(71) a. Anna lemaradt a vonatrol. (preferencialmente não-específico) Anna perdeu o trem.

b. A vonatrollemaradt Anna. (específico)

$\mathrm{O}$ trem, a Anna perdeu.

Ihsane e Puskás (2001) defendem que o DP o trem foi fronteado em (71b) para a projeção Top, e o fato de o Húngaro não poder frontear DPs que trazem informação nova evidencia esta análise - lembrando que Tópico é relacionado a informação velha. Os autores assumem que o DP em (71b) é específico, e isto o habilita a ser licenciado na projeção de Tópico frasal em Húngaro. Também comentam que isto é independente dos traços de definitude do DP.

A segunda evidência é mencionada por Mathieu (2009), que remete aos trabalhos de Holmberg (1999) e Chomsky (2001). Em norueguês e sueco, a mudança da ordem dos objetos está correlacionada à interpretação específica. Objetos não-específicos nunca mudam de posicionamento em nenhuma língua escandinava. Holmberg propõe que a mudança de ordem dos objetos está correlacionada ao movimento do verbo para Tópico. O exemplo a seguir, em Sueco, é apresentado por Holmberg (1999, p. 1).

(72) a. Jag kysstehenneinte $\left[\mathrm{VP}_{\mathrm{v}} \mathrm{t}_{\mathrm{o}} \mathrm{t}\right.$

Eu beijei ela não

b. ${ }^{(*)}$ Jag kysste inte henne.

Eu beijei não ela. 
(73) a. *Jag harhenneinte $\left[\mathrm{vp}_{\mathrm{v}}\right.$ kysst $\left.\mathrm{t}_{\mathrm{o}}\right]$

Eu tinha ela não beijado

b. Jag harintekyssthenne.

Eu tinha não beijado ela.

(74) a. *...att jag henneinte $\left[{ }_{\mathrm{VP}}\right.$ kysste $\left.\mathrm{t}_{\mathrm{o}}\right]$

Que eu ela não beijei

b. attjagintekysstehenne.

Que eu não beijei ela.

O autor mostra com os exemplos acima que se o verbo não pode se mover - porque o verbo auxiliar bloqueia a subida do verbo principal, no caso de (73a), ou porque não há movimento de verbo em sentenças encaixadas no Sueco, como mostra (74a) -, não há deslocamento do objeto. Holmberg postula que em (72a) temos subida do pronome fraco relacionada a movimento do verbo de $\mathrm{V}$ - para I - para $\mathrm{C}$, o que resulta em topicalização do verbo.

A terceira evidência é apresentada por Den Dikken (2006, p. 91) para o inglês. As inversões de predicado em sentenças copulares só são permitidas em sentenças equativas ou especificacionais. O predicado pode ocupar a posição mais alta quando for uma pseudoclivada específica. Mas o caso mais interessante ocorre com inversão locativa (ver (77)), pois neste caso a inversão é obrigatória.

(75) a. Brian is an excellent doctor.

O Brian é um excelente médico.

b. An excellent doctor is Brian.

Um excelente medico é o Brian.

(76) a. The Vietnam War and the Gulf War are examples of this.

A Guerra do Vietnã e a Guerra do Golfo são exemplos disso.

b. Examples of this are the Vietnam War and the Gulf War. Exemplos disso são a Guerra do Vietnã e a Guerra do Golfo.

(77) a. *Imogen expects on this wall to be hung a portrait of Brian. Imogen espera nesta parede que seja pendurado o retrato de Brian. b. On this wall Imogen expects to be hung a portrait of Brian. Nesta parede, Imogen espera que seja pendurado o retrato de Brian. 
Den Dikken (2006, p. 98, tradução nossa) aponta que “a Inversão Locativa dentro de uma sentença infinitiva é possível somente se o PP locativo aparecer em uma posição de tópico na sentença matriz"18.

Isto mostra que especificidade desencadeia movimento de várias categorias, não somente de adjetivos.

\section{Conclusões}

Defendemos neste trabalho que os adjetivos qualificativos pré-nominais provêm de movimento de uma posição mais baixa que o nome, à direita de $\mathrm{N}$, para a posição pré-nominal. Defendemos que seu movimento é motivado pelo determinante. Mostramos que, quando o DP é referencial, o determinante será concatenado numa posição de definitude. E se específico, DefP projetará TopP, uma projeção relacionada à especificidade por muitos autores, como Ihsane e Puskás (2001), entre outros. Essa projeção de tópico oferecerá um lugar de pouso para os adjetivos qualificativos, que, se movidos, só poderão ter leitura específica, pois a projeção de tópico não carrega traços de não-especificidade. Defendemos que se Def é específico, ele projeta ToP; caso contrário, não há projeção alguma relacionada à não-especificidade. Isso nos garante que o adjetivo não se moverá se não tiver leitura específica, o que capta a intuição trazida pelos dados.

\section{Referências}

ABNEY, S. P. The English noun phrase in its sentential aspect. Cambridge, Massachusetts: MIT Press, 1987.

$\mathrm{ABOH}$, E. et al. DP internal information structure: some introductory remarks. Lingua, p. 782-801, 2009.

BERNSTEIN, J. Topics in the syntax of nominal structure across romance. PhD Dissertation. New York: CUNY, 1993.

BHATT, R.; ANAGNOSTOPOULOU, E. Object Shift and Specificity: Evidence from ko-phrases in Hindu. In: DOBRIN, et al. Papers from the main session of CLS 32. 1996.

\footnotetext{
${ }^{18}$ No original: "Locative Inversion within the infinitival clause is possible only if the locative PP does not actually surface there but instead shows up in topic position in the matrix clause".
} 
BORGES NETO, J. O adjetivo e a construção do sintagma nominal: alguns problemas. Letras, Curitiba, n. 34, p. 28-38, 1995.

BORIK, O.; ESPINAL, M. T. Reference to kinds: definiteness and number. Barcelona: Universitat Autònoma de Barcelona, 2013.

BOSQUE, I. Sobre las diferencias entre los adjetivos relacionales y los calificativos. Revista Argentina de Linguistic, v. 9, n. 1-2, p. 9-48, 1993.

Adjective position and the interpretation of indefinites. In: GUTIERREZ-REXACH, J.; SILVA-VILLAR, L. (Ed.). Current issues in Spanish Syntax and Semantics. Berlin; New York: Mouton de Gruyter, 2001.

BOSQUE, I.; PICALLO, C. Postnominal adjectives in SpanishDPs. Linguistics, v. 32, p. 349-385, 1996.

CARLSON, G.; PELLETIER, F. (Eds.). The generic book. Chicago: University of Chicago Press, 1995.

CHOMSKY, N. Derivation by Phases. In: KENSTOWICZ, M. (Ed). Ken Hale: a life in Language. Cambridge, Massachusetts: MIT Press, 2001. p. 1-52.

CINQUE, G. Types of A'dependencies. Cambridge, Massachusetts: MIT Press, 1990.

. On the Evidence for partial N-movement in the Romance DP. 1993. Disponível em: < http://arcaold.unive.it/bitstream/10278/408/1/3.2.pdf $>$. Acesso em: 9 maio 2016.

. The syntaxofadjectives: a comparativestudy. Cambridge, Massachusetts: MIT Press, 2010.

CORNILESCU, A.; DINU, A. Adjectives and specificity. RRL, Bucureşti, v. LVIII, n. 4, p. 455-480, 2013.

CRISMA, P. Functional categories inside the noun phrase: a study on the distribution of nominal modifiers.Tese.University of Venice. 1990.

. On adjective placement in romance and germanic event nominals. 1993. Disponível em: <http://arcaold.unive.it/ bitstream/10278/410/1/3.4.pdf $>$. Acesso em: 9 maio 2016.

. On the configurational nature of adjectival modification, 1996. In: ZAGONA, K. (Ed.). Grammatical Theory and Romance Languages. Amsterdam: John Benjamins, 1996. 
CYRINO, S.; ESPINAL, M. T. Bare nominals in BP: more on the DP/NP analysis. Natural Language and Linguistic Theory, set. 2014.

DEMONTE, V. A minimal account of Spanish Adjective position and interpretation. In: FRANCO, J. A.; LANDA, A.; MARTIN, J. (Eds.). Grammatical analyses in Basque and Romance Linguistics. Amsterdam: John Benjamins, 1999.

. Meaning-form correlations and adjective position in Spanish. In: MCNALLY, L.; KENNEDY, C. Adjectives and adverbs. Oxford: Oxford University Press, 2008. p. 71-100.

DEN DIKKEN, Marcel. Relators and Linkers: The Syntax of Predication, Predicate Inversion, and Copulas. Linguistic Inquiry 47. Cambridge, MA: MIT Press, 2006.

DIESING, M. Indefinites. Cambridge: MIT Press, 1992.

DONNELLAN, Keith. Reference and definite descriptions. The Philosophical Review, v. 75, n. 3, p. 281-304, 1966.

ENC, M. The semantics of specificity. Linguistic Inquiry, v. 22, n. 1, p. $1-25,1991$.

ERNST, Thomas. The Syntax of Adjuncts. Cambridge University Press: Cambridge, 2004.

ESPINAL, M. T.; MCNALLY, L. Bare nominals and incorporating verbs in Catalan and Spanish. Journal of Linguistics, 47, p. 87-128. 2011.

FODOR, Janet. The Linguistic Description of Opaque Context. Tese de Doutorado. Massachusetts Institute of Technology.1970.

FODOR, J.; SAG, I. Referential and quantificational indefinites. Linguistic and Philosophy, p. 355-398, 1982.

GIORGI, A.; LONGOBARDI, G. The syntax of noun phrase: configuration, parameters and empty categories. Studies in Language, v. 16, n. 1, p. 201-205, 1992.

GIUSTI, G. Is there a FocusP and a TopicP in the noun phrase structure? Working Papers in Linguistics, v. 6, n. 2, p. 105-128, 1996.

. Parallels in clausal and nominal periphery. In: FRASCARELLI, M. (Ed.) Phases of Interpretation. Berlin: Mouton de Gruyter, 2006. p.163-184. HOLMBERG, A. Remarks on Holmberg's Generalization. Studia Linguistica, v. 53, p. 1-39, 1999. 
IHSANE, T.; PUSKÁS, G. Specific is not definite. Generative Grammar in Geneva, v. 2, p. 39-54, 2001.

KATO, M. A sequência Adj $+\mathrm{N}$ em português e o princípio da harmonia transcategorial. Letras\&Letras, v. 4, n. 1-2, p. 205-13, 1988.

LAMBRECHT, K. Information structure and sentence form: topic, focus and the mental representations of discourse referents. Cambridge: Cambridge University Press, 1994.

LEMLE, M. A ordem dos adjetivos no sintagma nominal inglês: implicações para a teoria gramatical. In: ENCONTRO NACIONAL DE LINGUÍSTICA, 3., 1979, Rio de Janeiro. Anais... Rio de Janeiro: PUC, 1979.

LEONETTI, M. El artículo. In: BOSQUE, I; DEMONTE, V. Gramática descriptiva de la lengua española. Madrid: Espasa, 1999. p. 787-890.

. Remarks on focus structure and non-specificity. In: ESPINAL, M. T.; LEONETTI, M.; MCNALLY, L. (Eds.). Proceedings of the IV NEREUS International Workshop "Definiteness and the DP Structure in Romance Languages”. Konstanz: Universität Konstanz, 2009.

LONGOBARDI, G. Reference and proper names: A theory of N-Movement in syntax and logical form. Linguistic Inquiry, v. 25, n. 4, p. 609-665, out. 1994.

LYONS, C. Definiteness. Cambridge: Cambridge University Press, 1999. MATHIEU, E. From local blocking to Cyclic Agree: the role and meaning of determiners in the history of French. In: GHOMESHI, J.; PAUL, I.; WILTSCHKO, M. (Eds.). Determiners: Universals and variation. Amsterdam: John Benjamins, 2009. p. 123-158.

MCNALLY, L.; BOLEDA, G. Relational adjectives as properties of kinds. In: BONAMI, O.; HOFHERR, P. C. (Eds.). Empirical Issues in Syntax and Semantics 5, p. 179-196, 2004. Disponível em: <http:// www.semanticsarchive.net/Archive/jU4MWYwZ/mcnally-boleda.pdf $>$. Acesso em: 20 out. 2012.

MAGALHÃES, T. M. V. A valoração de traços de concordância dentro do DP. DELTA, São Paulo, v. 20, n. 1, 2004. p. 149-170.

MULLER, A.; NEGRÃO, E.; NUNES-PEMBERTON, G. Adjetivos no português do Brasil: predicados, argumentos ou quantificadores? 
In: ABAURRE, M. B. M.; RODRIGUES, A. C. S. (Org.). Gramática do Português Falado: novos estudos descritivos. v. III. Campinas: UNICAMP, 2002. p. 317-344.

PARTEE, B. Opacity, coreference, and pronouns. In: DAVIDSON, D.; HARMAN, G. (Eds.). Semantics of Natural Language. Dordrecht: Reidel, 1972. p. 415-441.

. Privative adjectives: subsective plus coercion. 2010. Disponível em: $<\mathrm{http}: / /$ people.umass.edu/partee/docs/ParteeInPressKampFest.pdf $>$. Acesso em: 2014.

PICALLO, C. A mark of specificity in indefinite nominal. 1994. Disponível em: <http://ddd.uab.cat/pub/cwpil/1132256Xv4n1p143.pdf >. Acesso em: 2014.

RIJKHOFF, J. Order in the noun phrase of the languages of Europe. In: SIEWIERSKA, A. (Ed.). Constituent order in the languages of Europe. Berlin; New York: Gruyter, 1998. p. 321-382.

RIZZI, L. The fine structure of the left periphery. In: HAEGEMAN, L. (Ed.). Elements of Grammar. Dordrecht: Kluwer, 1997. p. 281-337.

ROBERTS, I. Diachronic Syntax. Oxford Textbooks in Linguistics. New York: Oxford University Press, 2007.

SIEWIERSKA, A.; UHLIROVA, L. An overview of word order in Slavic languages. In: SIEWIERSKA, A. (Ed.). Constituent Order in the Languages of Europe. Berlin; New York: De Gruyter, 1998. p. 105-149.

VON HEUSINGER, K. Specificity and definiteness in sentence and discourse structure. Journal of Semantics, 19, p. 254-274, 2002. Disponível em: $<$ http://germanistischelinguistik.phil-fak.uni-koeln.de/ kvh/pub/pub02/SpeDefSenDisStr/02SpecDef.pdf $>$. Acesso em: $18 \mathrm{fev}$. 2013.

. Specificity. In: VON HEUSINGER, K.; MAIENBORN, C.; PORTNER, P. (Eds.) Semantics: an international handbook of natural language meaning. v. 2. Berlin; Boston: De Gruyter, 2011. 